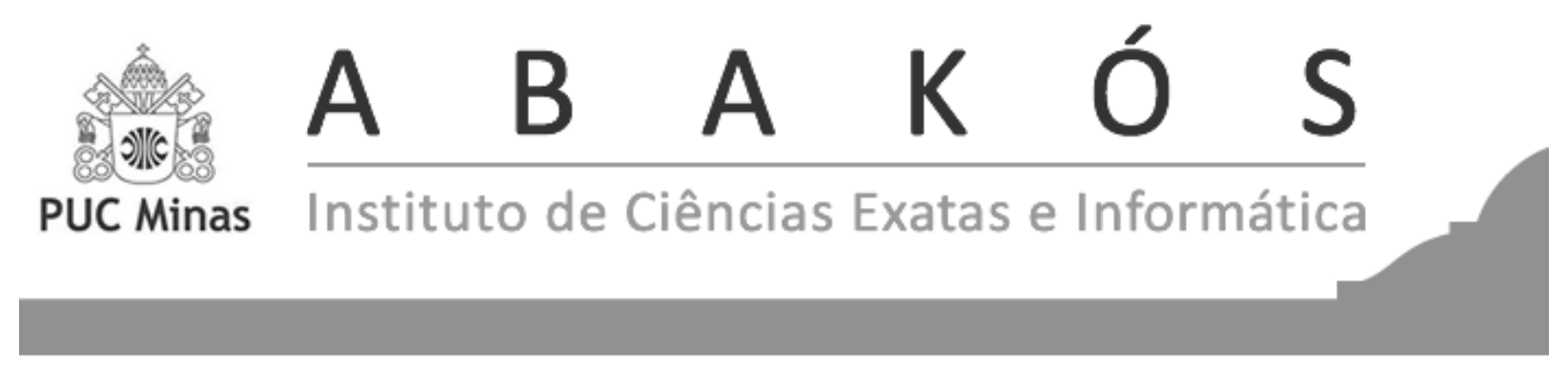

\title{
Formação Inicial e Continuada de Professores de Matemática no Contexto da Realidade Aumentada*
}

Initial and Continuing Training of Mathematics Teachers in the Context of Augmented Reality

\author{
Daniela Vieira Cunha ${ }^{1}$ \\ Celina Aparecida Almeida Pereira $\mathrm{Abar}^{2}$
}

\begin{abstract}
Resumo
Este artigo é resultado de um projeto de formação de professores de Matemática para o uso de tecnologias digitais e com propostas de ações inovadoras. Tem como objetivo identificar, a partir de reflexões apresentadas pelos participantes de duas oficinas realizadas no contexto da Realidade Aumentada (RA), contribuições desse processo formativo. Aspectos do ciclo expansivo na perspectiva de Engeström (1987) foram considerados nas análises dos momentos de participação dos professores nas atividades desenvolvidas. Nos últimos anos e, atualmente, a pesquisa e a prática mostraram que o uso da tecnologia pode desempenhar um papel importante na compreensão de conteúdos matemáticos. O professor deve estar preparado para o uso das tecnologias digitais de informação e comunicação (TDIC) na prática docente, para que possa aprimorar o processo de ensino e de aprendizagem de conteúdos matemáticos. Por ser uma tecnologia atual, muitos docentes desconhecem a importante contribuição da RA como uma prática pedagógica. Este artigo discorre sobre duas propostas de oficinas de formação inicial e de formação continuada no contexto da RA por meio de manipulação de sólidos. Os participantes foram professores em formação inicial e professores do Ensino Fundamental II, e os aplicativos de RA utilizados foram Augment e GeoGebra 3D com RA. A proposta despertou o interesse de professores pela possibilidade e capacidade de ensinar de forma divertida e confortável para o aluno.
\end{abstract}

Palavras-chave: Formação continuada. Tecnologias digitais de informação e comunicação. Realidade aumentada.

\footnotetext{
* Submetido em 22/09/2020 - Aceito em 29/06/2021

${ }^{1}$ Professora na Universidade Presbiteriana Mackenzie.Aluna de Pós-Doutorado pelo Programa de Estudos PósGraduados em Educação Matemática da PUC São Paulo, Brasil-daniela.cunha@gmail.com

${ }^{2}$ Professora do Programa de Estudos Pós-Graduados em Educação Matemática da PUC São Paulo, Brasil- abarcaap@pucsp.br
} 


\begin{abstract}
We report results on the elaboration and application of a project for training Mathematics teachers to use digital technologies and propose innovative actions. The aim is to identify contributions to the teachers' formative process from the reflections during their participation in two workshops held in the Augmented Reality (AR) context. We analyzed the teachers' performance in the activities, considering aspects of the expansive cycle from the perspective of Engeström (1987). Recently, research and practice have shown that the use of technology can play a relevant role in the understanding of mathematical content. The teacher must be prepared to use digital information and communication technologies - TDIC to improve the teaching and learning of mathematical content. Being a current technology, many teachers are unaware of its importance to AR as a pedagogical practice. We discuss two proposals for initial and continuing education workshops, in the context of $\mathrm{AR}$, through the handling of solids. The participants were teachers in training and teachers at elementary school II. The AR applications used were Augment and GeoGebra 3D with AR. The teaching proposal aroused the interest of teachers for the ability to teach in a fun and comfortable way for the student.
\end{abstract}

Keywords: Continuing education. Digital information and communication technologies. Augmented reality. 


\section{INTRODUÇÃO}

Nos últimos anos, a pesquisa e a prática mostraram que o uso da tecnologia pode desempenhar um papel importante, ajudando os alunos a representar, identificar e explorar os comportamentos de vários relacionamentos matemáticos. Mas, a tecnologia por si só não resolve nenhum problema educacional. Um objetivo importante durante o aprendizado da matemática é que professores e alunos desenvolvam uma apreciação e uma disposição para praticar a investigação matemática genuína.

A ideia é que professores e alunos devam colocar questões, pesquisar vários tipos de representações e apresentar diferentes argumentos durante a interação com as tarefas matemáticas e envolver as tecnologias digitais que se tornaram um componente importante há algum tempo. Assim, o papel dos professores vai além de encarar a matemática como um conhecimento fixo; ao invés disso, os professores poderiam conceituar o estudo da matemática como uma atividade de aprendizagem na qual é importante participar para identificar, explorar e comunicar ideias vinculadas a situações matemáticas e as tecnologias digitais podem desempenhar um papel facilitador nesse processo.

Segundo Moreno-Armella e Sriraman (2010):

Uma falta de perspectiva pode dar a impressão de que foi apenas nos últimos anos que os educadores começaram a considerar o papel da tecnologia em nossos sistemas educacionais. O que mudou nos últimos anos foi a compreensão da natureza do papel da tecnologia nos processos de aprendizado dos alunos. É, então, importante ter uma perspectiva de longo prazo para sermos capazes de medir o papel que as tecnologias computacionais podem desempenhar na educação contemporânea. (MORENO-ARMELLA; SRIRAMAN, 2010, p. 221, Tradução das autoras).

Temos, como exemplo concreto, os dias atuais da pandemia de Covid-19, em que escolas e professores tiveram que se reinventar na utilização da tecnologia para tentar manter uma convivência escolar remota. Novamente, as dificuldades tecnológicas ficaram expostas tanto para muitos que não possuem este acesso, como para outros, mais privilegiados, que perceberam a importância da presença dos familiares, o que é sempre solicitado nas orientações pedagógicas, para o apoio na realização das atividades propostas pelas respectivas escolas. São momentos que provocam reflexões e, certamente, modificam o papel das tecnologias na educação, tanto nas escolas como fora delas.

Entendemos que no cenário anterior à pandemia, no ambiente escolar presencial, utilizava-se, na medida da necessidade, a tecnologia na prática docente como apoio às práticas pedagógicas, mas as pesquisas evidenciavam-na há tempos como essencial. De acordo com Santos (2011) é necessário repensar e reconsiderar as formas de ensinar. O uso das tecnologias pode proporcionar a aquisição de competências, transformando as atividades de apoio ao ensino em atividades constantes, adaptando à diversidade e ao contexto dos alunos.

O desafio é incorporar Tecnologias Digitais de Informação e Comunicação (TDIC), utilizar parte da potencialidade destas tecnologias na educação matemática e, assim, tentar pro- 
duzir significados nos processos de ensino e de aprendizagem. As tecnologias, quando bem empregadas, articulam teoria e prática na formação do conhecimento de maneira significativa, principalmente para alunos que apresentam dificuldades em aprender conteúdos matemáticos mais visuais, tais como figuras tridimensionais, gráficos e ideias que contenham movimento. (AGOSTINHO; GROENWALD, 2020; OLIVEIRA, 2018; TORI, 2010; CARDOSO; COIMBRA; MATEUS, 2018).

Para que a transformação digital na escola, especificamente na sala de aula, se torne realidade, o professor deve estar preparado para adaptar a tecnologia às suas práticas de ensino. $\mathrm{O}$ professor carece de aprender a usar a tecnologia e decidir pela ferramenta que melhor se adequa a cada assunto e a cada turma. (OLIVEIRA, 2014).

Apesar da convivência diária com diferentes tecnologias, os professores, em sua maioria, têm receio de implantar a tecnologia em sala de aula. Isso se deve a diferentes fatores, dentre eles: a não familiaridade do professor com dispositivos móveis, resistência em explorar uma área desconhecida para ele e tão dominada pelos alunos, e insegurança em usar ferramentas (aplicativos) de forma a integrá-las, eficientemente, ao seu planejamento. (PACHECO; LOPES, 2019; AGOSTINHO; GROENWALD, 2020). Isso irá mudar após a pandemia de Covid-19, quando voltarmos à realidade presencial?

Acredita-se que é importante que o professor esteja preparado para que passe a ter familiaridade com as tecnologias e segurança na aplicação delas. Assim, a formação continuada de professores é essencial e contribui fundamentalmente no processo de atualização tecnológica das práticas pedagógicas. Os professores devem se atualizar constantemente para poder, cada vez mais, se aproximarem da realidade do seu aluno e tornar o ensino mais eficiente e a aprendizagem mais confortável e tranquila.

Neste trabalho é apresentado um relato de propostas de duas oficinas realizadas, de formação continuada e formação inicial, para o ensino de realidade aumentada (RA) como recurso no processo de ensino-aprendizagem de Matemática.

$\mathrm{Na}$ oportunidade de reunir professores espera-se compartilhar a necessidade de formação e/ou atualização na área de tecnologias para o ensino da Matemática e identificar, a partir de reflexões apresentadas pelos participantes, contribuições desse processo formativo, obtendo dados para a preparação de outras formações com designs (MAZZARDO et al., 2016) aprimorados e motivadores.

\section{PERCURSOS TEÓRICOS}

Em nossa concepção, toda atividade de ensino ou ação educativa é conduzida por objetivos a serem alcançados pelo trabalho docente, que pode ser aprimorada por meio de ações colaborativas com seus pares e, também, com a academia.

É imprescindível que as tecnologias sejam associadas às práticas pedagógicas e, consequentemente, ao processo de ensino e aprendizagem de forma que haja uma mudança no ensino 
de Matemática. Para que essa transformação digital aconteça no ambiente escolar, o professor precisa conhecer os recursos tecnológicos e sentir segurança suficiente no seu manuseio. Consequentemente, a qualificação da formação docente é fundamental (ARTIGUE, 2010).

O professor precisa escolher uma ferramenta tecnológica para que seja uma ferramenta pedagógica, e essa escolha só é possível a partir do momento que ele conhece a tecnologia e já faz algum uso dela. A experiência do professor com a ferramenta é primordial para uma escolha mais eficiente.

Muitos professores possuem o pré-conceito de que o uso da tecnologia é difícil e preferem não usar recursos tecnológicos em sala de aula. Esse é um dos motivos que impulsionam os projetos de formação continuada de professores, a fim de desmistificar a dificuldade de implantação de tecnologias no processo de ensino-aprendizagem e diminuir a resistência do professor.

Uma formação continuada deve proporcionar o contato prático do professor com os novos recursos, e permitir a exploração das ferramentas tecnológicas para que ele reflita sobre o uso delas, correlacione com os conteúdos e adquira confiança no seu manuseio.

Bittar (2006) afirma que a incorporação das tecnologias acontecerá efetivamente somente quando o professor vivenciar o processo, ou seja, quando a tecnologia representar um instrumento importante de aprendizagem para todos, inclusive (e, sobretudo) para o professor, afinal somos reflexo de nossa aprendizagem.

\subsection{Aspectos da Teoria da Atividade}

A Teoria da Atividade é uma teoria educacional ligada à concepção de aprendizagem sociointeracionista. Parte-se do pressuposto que a atividade humana não é um processo natural e que a atividade pode ser considerada como o que se realiza por um motivo e com uma finalidade. Assim, a atividade constitui-se de um conjunto de ações e operações direcionadas por um motivo, para atingir determinada finalidade. Toda ação depende sempre de um esforço consciente. O motivo é o que impulsiona a determinar o objetivo e a operação é a maneira de se executar uma ação. As operações podem ser diferentes, dependendo justamente das condições em que a ação é realizada (OLIVEIRA, 2002).

A Teoria da Atividade vem sendo utilizada nas abordagens de trabalhos sobre as relações homem-computador, justamente por possibilitar a análise de atividades mediadas por TDIC (ASSIS, 2005).

Apoiadas nas perspectivas de Engeström (1987), entendemos como uma necessidade o professor agir com intencionalidade no momento da elaboração de uma atividade didática para a criação de um recurso ou de participação em um projeto de formação continuada.

Segundo Engeström (1987), no plano individual uma atividade é composta de três elementos, sendo eles, o sujeito, os objetos e as ferramentas (artefatos) de mediação entre sujeito e objetos; no plano coletivo existe outro elemento nas relações entre sujeito e ambiente: a comunidade com suas regras, implícitas e explícitas, que norteiam as relações dos sujeitos na 
comunidade e a divisão de trabalho como forma de organização da comunidade em relação ao processo de transformação dos objetivos para atingir o resultado. A Figura 1 ilustra esta estrutura de uma atividade vista segundo o modelo sistêmico proposto por Engeström (1987).

\section{Figura 1 - Estrutura de uma atividade}

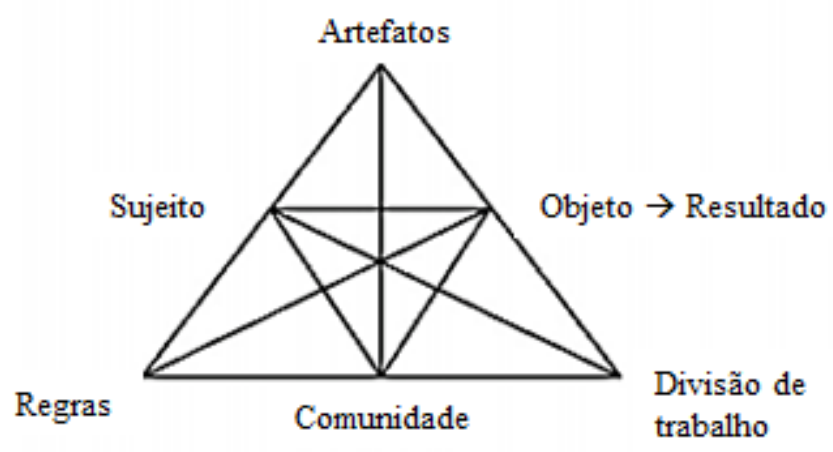

Fonte: Engeström (1987).

Podemos melhor compreender esses conceitos aplicando-os ao contexto de formação continuada, que é o tema central deste projeto de formação de professores de Matemática para o uso de RA. O Quadro 1 apresenta a atividade didática e os componentes envolvidos.

\section{Quadro 1 - Componentes da atividade}

\begin{tabular}{|c|c|c|}
\hline \multicolumn{3}{|c|}{ Atividade - Oficina de formação inicial e continuada em RA } \\
\hline Componente & Definição & Aplicação \\
\hline Sujeito & $\begin{array}{l}\text { Agente cujo comportamento } \\
\text { se pretende analisar. }\end{array}$ & $\begin{array}{l}\text { Participantes da oficina (professo- } \\
\text { res de Matemática). }\end{array}$ \\
\hline Objeto & $\begin{array}{l}\text { Material bruto sobre o qual } \\
\text { o sujeito vai agir, mediado } \\
\text { pelas ferramentas, em inte- } \\
\text { rações contínuas com outras } \\
\text { pessoas. }\end{array}$ & $\begin{array}{l}\text { Oficina elaborada com o objetivo de } \\
\text { apresentar e despertar interesse para } \\
\text { as ferramentas de RA no ensino da } \\
\text { Matemática. }\end{array}$ \\
\hline Resultado & Significado do objeto. & $\begin{array}{l}\text { Aperfeiçoamento do conhecimento } \\
\text { do professor, de acordo com o } \\
\text { objeto definido, ou seja, conheci- } \\
\text { mento sobre ferramentas de RA que } \\
\text { podem auxiliar no ensino da Mate- } \\
\text { mática. }\end{array}$ \\
\hline Artefato & $\begin{array}{l}\text { Objetos (materiais ou ideais) } \\
\text { utilizados pelo sujeito para } \\
\text { atingir seu resultado. }\end{array}$ & $\begin{array}{l}\text { Aplicativos de realidade aumen- } \\
\text { tada, projetor, celular. }\end{array}$ \\
\hline Regras & $\begin{array}{l}\text { Refere-se às normas explíci- } \\
\text { tas e convenções que restrin- } \\
\text { gem a ação dentro do sistema } \\
\text { de atividade }\end{array}$ & $\begin{array}{l}\text { Os participantes são convidados a } \\
\text { realizar as práticas da oficina e, em } \\
\text { determinados momentos, também } \\
\text { expõem seus resultados e aprendi- } \\
\text { zados. }\end{array}$ \\
\hline Comunidade & $\begin{array}{l}\text { Aqueles que tomam parte na } \\
\text { realização do objeto. }\end{array}$ & Participantes e instrutora da oficina. \\
\hline Divisão de trabalho & $\begin{array}{l}\text { Divisão de tarefas entre os in- } \\
\text { divíduos da comunidade. }\end{array}$ & $\begin{array}{l}\text { Divisão das ações de todos os en- } \\
\text { volvidos na oficina. }\end{array}$ \\
\hline
\end{tabular}


O principal aspecto da escolha da Teoria da Atividade, na visão de Engeström (1987), como uma opção teórica e metodológica, está no conceito de ciclo expansivo, utilizado neste estudo e, possivelmente, em propostas futuras com base na análise de dados coletados neste projeto, que permitirão novas propostas de formação a partir da experiência realizada.

De acordo com Engeström (1987), a ascensão do abstrato para o concreto é alcançada pelas ações de aprendizado que, juntas, formam um ciclo expansivo. O ciclo expansivo, Figura 2 , começa com o sujeito questionando uma determinada prática e, gradualmente, expandindo para o desenvolvimento de uma nova prática. Seu ponto de partida caracteriza-se pela abstração, que, no decorrer do processo, converte-se em um sistema concreto de múltiplas manifestações e constantes desenvolvimentos.

\section{Figura 2 - Sequência do ciclo expansivo de Engeström}

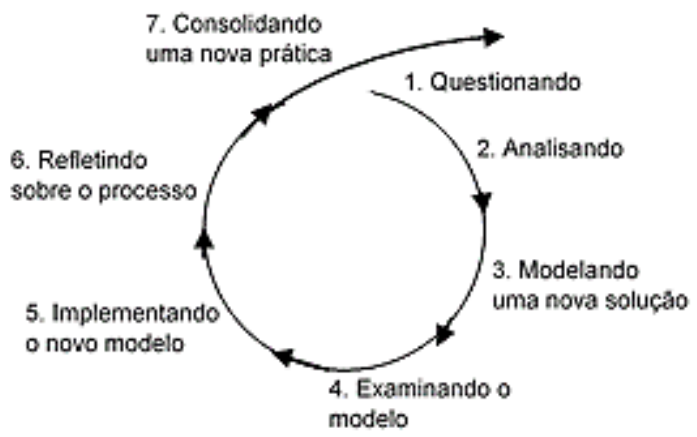

Fonte: Engeström (1987).

Para o autor, a sequência ideal de ações de um ciclo expansivo caracteriza-se pelas sete etapas descritas a seguir e que estão relacionadas com o desenvolvimento das propostas apresentadas na formação continuada:

a) $1^{a}$ etapa "Questionando": questionamento, crítica ou rejeição de alguns aspectos da prática corrente. Como os professores foram convidados para participarem das oficinas, espera-se, nessa etapa, que os questionamentos sejam anteriores à efetivação da $1^{a}$ etapa. Se considerarmos o questionamento associado a uma atividade proposta em uma formação continuada, ele é válido e importante para entender o objetivo da atividade;

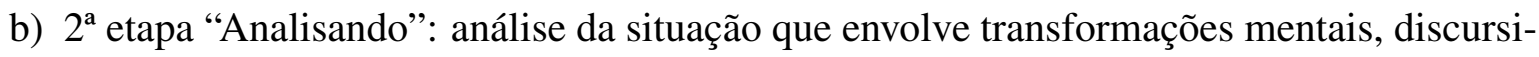
vas ou práticas da situação em questão para descobrir causas ou mecanismos exploratórios. Nas oficinas, o papel de cada participante não foi isolado e proporcionou momentos de reflexão sobre a situação. Houve questionamento sobre a forma como a teoria foi apresentada e vinculada com a prática através do uso da ferramenta de RA;

c) $3^{\text {a }}$ etapa "Modelando": construção de um modelo da nova ideia, que explique e ofereça uma solução para a situação dada como problema. Nessa etapa, a escolha metodológica de realização de oficinas como modelo foi evidenciada. Participantes tentam levar a realidade e a experiência deles para a oficina e sugerem formas diferentes para aprimorar a atividade (prática); 
d) 4 etapa "Examinando o modelo": experimentação do modelo, visando perceber sua dinâmica, potencialidade e limitações. Reconhecemos que a relação pesquisador-professor é, em si, um objeto de observação, que faz parte do campo de atuação e, portanto, sujeito à negociação explícita entre as partes, gerando questionamentos sobre a proposta;

e) 5a etapa "Implementando o modelo": com a descoberta das possíveis limitações e potencialidades do modelo, segue-se para a concretização do mesmo por meio de sua aplicação prática, visando salientar a dinâmica mais adequada para cada situação. Nessa etapa, uma atividade da oficina é colocada em prática e observa-se o quão consciente é o participante sobre a necessidade de atualização de suas práticas pedagógicas rotineiras com o uso da tecnologia;

f) 6a etapa "Refletindo": avaliação do novo processo. Nesta etapa é feita a coleta de dados para preparação de atividades mais próximas do dia a dia de sala de aula e mais adaptada e coerente com cada contexto escolar. As reflexões colaboram para a preparação de formações com designs aprimorados e verifica-se as contribuições da oficina no processo formativo;

g) $7^{\text {a }}$ etapa "Consolidando": estabelecimento de uma nova forma de prática do indivíduo na comunidade.

Para Engeström (1987), o processo que envolve o ciclo expansivo é uma contínua construção e resolução de tensões e contradições em um sistema de atividade que envolve objetivo, ferramentas mediadoras e as perspectivas dos participantes envolvidos.

A principal implicação do sistema de atividade como unidade de análise é que as intervenções precisam ser incorporadas e contextualizadas na atividade de vida significativa dos participantes.

Uma intervenção que se limita à transformação de ações e ignora a dinâmica motivacional decorrente do objeto da atividade pode ser tecnicamente eficaz no curto prazo, mas é improvável que tenha influência formativa duradoura no longo prazo.

Admitimos, neste estudo, que as atividades analisadas correspondem àquelas de cada etapa do desenvolvimento das oficinas, especificamente das práticas abordadas e inseridas no ciclo expansivo, que foram possíveis de observação até a etapa 6.

\subsection{Tecnologias Digitais de Informação e Comunicação - TDIC}

Pesquisas acadêmicas e a experiência docente das autoras constatam as dificuldades dos alunos ao estudarem assuntos referentes à Matemática, tais como representações das formas tridimensionais. A boa vontade do professor, os livros e a lousa nem sempre são suficientes para o ensino e a aprendizagem de certos conteúdos matemáticos, principalmente os conteúdos que exigem visualização e abstração. (MACEDO, 2018). 
O uso das TDIC pode proporcionar uma análise diferente do conteúdo ensinado e contribuir para a formação dos conceitos matemáticos. A inserção das TDIC em sala de aula não é a solução "mágica" para os problemas de aprendizagem matemática, mas, se usada de forma eficaz e com simplicidade, apresenta ser uma boa opção educacional.

Consideramos as TDIC com um conjunto de dispositivos digitais e aplicações tecnológicas que, geralmente, são utilizados associados à Internet. As tecnologias são capazes de desenvolver diferentes sistemas de representação e de pensamento, principalmente quando aplicadas à construção do conhecimento e possuem potencial para produzir uma melhor eficiência nos processos de ensino e de aprendizagem (ROBERTO, 2012).

O uso consciente das TDIC na educação pode trazer benefícios, tais como: (1) gerar objetos educacionais capazes de aperfeiçoar as aulas e os recursos; (2) contribuir para a assimilação de conceitos e na potencialização dos métodos de estudo dos alunos; (3) melhorar as metodologias de ensino dos professores, e (4) ajudar na produção de material didático de melhor qualidade (TORI, 2010).

É necessária uma formação continuada do educador para que ele consiga levar a inclusão da tecnologia digital para a sua atuação diária. Os alunos já estão conectados e usam a tecnologia com muita facilidade, própria de um nativo digital. O grande desafio é aflorar no aluno, por vezes desatento, a mesma atenção e concentração multifocal de quando usa uma tecnologia e está conectado.

Com uma formação continuada, o professor poderá redescobrir a sua função para o ensino e para a aprendizagem, como um arquiteto de construção do conhecimento e não como um detentor de conhecimento e se adequar a uma nova forma de educar através do uso de TDIC (CARDOSO; LAMOUNIER, 2006).

As principais TDIC utilizadas no ensino, atualmente, são os computadores e softwares, os smartphones, tablets e aplicativos. Esses dispositivos e ferramentas proporcionam a seus usuários múltiplas experiências de interatividade, o que exige um comportamento diferente do aluno, acostumado a ser passivo diante da apresentação formal do conhecimento baseada na transmissão de informações.

Os dispositivos digitais móveis, utilizados no dia a dia das pessoas, trazem, dentre suas funcionalidades, a capacidade de executar a Realidade Aumentada (RA). Considerando essa disponibilidade e a capacidade dos smartphones da maioria dos alunos em executar a RA, essa pode ser usada como um recurso didático-pedagógico no processo de ensino-aprendizagem de Matemática, no processo de interação do aluno e colaborar nas dificuldades cognitivas dos alunos em determinados conceitos matemáticos (OLIVEIRA, 2018).

A Realidade Aumentada é um conjunto de técnicas computacionais que, a partir de um dispositivo tecnológico, gera, posiciona e mostra elementos virtuais integrados a um cenário real que podem ser visualizados, em tempo real, através da tela de um dispositivo móvel. (KIRNER; TORI, 2006). O usuário, durante toda a interação com a tecnologia, mantém o senso de presença no mundo real.

Quando se pensa em RA, dificilmente lembra-se de como essa tecnologia pode ser útil 
em áreas do cotidiano, como, por exemplo, na Matemática. Ela pode ser usada na prática pedagógica do professor de Matemática para amenizar as dificuldades enfrentadas pelos alunos na visualização, abstração e interpretação de conteúdo específico. O conteúdo estudado passa a ter mais sentido e significado para o aluno, pois a RA permite acesso às informações de diferentes formas (som, imagem e vídeo). E o aluno, tendo sua curiosidade e sua criatividade instigadas, passa a interagir com a RA e se interessa pelo conteúdo estudado. (SILVA; VASCONCELOS, 2019).

Segundo Cardoso e Lamounier (2006, p. 305), "essa tecnologia, portanto, tem potencial de colaborar no processo cognitivo do aprendiz, proporcionando não apenas a teoria, mas também a experimentação prática do conteúdo em questão”. Segundo Rodrigues, Pinto e Rodrigues (2010, p. 87):

A introdução da RA na matemática, por exemplo, pode eliminar uma das grandes dificuldades do aluno: visualizar um problema complexo de geometria. Ela fornece a professores e estudantes um método intuitivo e colaborativo de aprender. Os alunos veem os objetos tridimensionais, sem precisar imaginá-los ou desenhá-los numa folha de papel. (RODRIGUES; PINTO; RODRIGUES, 2010, p. 87).

A RA é um convite ao professor para que amplie e reformule suas práticas pedagógicas desenvolvendo estratégias didáticas inovadoras que contribuam para que o aluno participe ativamente das experiências de aprendizagem e escolha novos caminhos na construção conjunta do conhecimento (MARTINS, 2009). É também um convite para o processo de formação continuada do professor, para que consiga utilizar o recurso tecnológico de RA, conhecer como utilizar e como inserir no planejamento de aula para que não gere apenas uma automação de repetição mecânica, mas sim um processo de construção de conhecimento.

Existem diferentes aplicativos de RA disponíveis para download e sem qualquer custo para o usuário. Dentre eles, Augment e GeoGebra 3D com RA, que foram utilizados nos dispositivos móveis dos participantes das oficinas e apresentados nesse trabalho.

\section{Augment}

(AUGMENT, 2020) é uma aplicação para dispositivo móvel que permite a visualização de modelos 3D em uma RA, integrada em tempo real em seu tamanho e ambiente verdadeiro. Disponível em plataformas Android e IOS, o que facilita o acesso a maior parte dos dispositivos móveis, hoje no mercado.

Essa aplicação é muito utilizada na área de marketing e de arquitetura para apresentação de projetos com vistas 3D em ambientes reais. Por essa razão, a ferramenta não apresenta recursos matemáticos que permitem uma interação numérica mais específica com o objeto 3D projetado no cenário real.

A razão de escolha da ferramenta para uma oficina de formação inicial e continuada de professores de Matemática foi devido à sua facilidade de manipulação de RA por iniciantes na tecnologia. Augment é uma ferramenta ideal para um primeiro contato com a realidade aumentada.

\section{GeoGebra 3D}


O aplicativo GeoGebra 3D com RA (GEOGEBRA, 2020) cria e manipula construções geométricas em 3D através de suas características matemáticas e pode ser usado em dispositivos móveis com câmera que executam os sistemas operacionais Android e IOS. Na época das oficinas, nem todos os aparelhos Android podiam executar o GeoGebra 3D com RA. Na página web do aplicativo existe uma lista de dispositivos móveis com os aparelhos Android que conseguem executá-lo.

Esse aplicativo foi desenvolvido especificamente para o ensino de Matemática. Através da ferramenta é possível manipular objetos $3 \mathrm{D}$, movimentando-os na tela sobre o cenário real e permitindo alterar as características matemáticas destes objetos.

Na página web do aplicativo é possível encontrar um acervo grande de material didático, ideias de atividades e manuais de ajuda para que o professor de Matemática possa desenvolver ambientes de aprendizado exploratórios e dinâmicos.

\section{PROCEDIMENTOS METODOLÓGICOS}

As oficinas de formação inicial e continuada foram ofertadas pelo Laboratório de Matemática da Faculdade de Computação e Informática (FCI), na Universidade Presbiteriana Mackenzie (UPM), como parte inicial de um projeto de pesquisa para a formação inicial e continuada de professores, desenvolvido em conjunto com o Programa de Estudos Pós-Graduados em Educação Matemática da Pontifícia Universidade Católica de São Paulo, PUC-SP, respectivas instituições das pesquisadoras.

A finalidade das duas oficinas foi o suporte tecnológico aos professores participantes, na tentativa de conscientizá-los, incentivá-los e motivá-los para a transformação digital em sala de aula. Essa transformação deve ser uma decisão do professor, que precisa estar seguro e confiante no uso das TDIC, em conjunto com as tradicionais práticas pedagógicas na criação de recursos para sua prática docente.

As oficinas foram desenvolvidas com o intuito de apresentar as ferramentas de RA (Augment e GeoGebra 3D) e seus recursos, para que os participantes pudessem se familiarizar com a tecnologia e sentir segurança para aplicá-las na sua atuação docente. A troca de experiências e reflexões, entre participantes e instrutor, sobre a prática pedagógica no ensino da Matemática aconteceram de forma motivadora e efetiva, enriquecendo consideravelmente as ações praticadas nas oficinas.

Duas oficinas, denominadas Oficina1 e Oficina2, foram tecnicamente desenvolvidas com foco no uso da RA no ensino de Geometria Espacial. Algumas figuras geométricas foram utilizadas para apresentar a tecnologia e a ferramenta de RA, que foi o objetivo principal. O conteúdo matemático associado à Geometria Espacial não foi explorado de forma efetiva, pois, para um primeiro encontro, esse aprofundamento seria inviável. É importante que o usuário conheça o ambiente antes de iniciar o seu uso propriamente dito.

Ressalta-se que essa é a etapa inicial de um projeto e o resultado desejado era expli- 
citar o quão consciente os participantes estão sobre a necessidade de atualização tecnológica para aplicação em sala de aula, e coletar dados para a preparação de formações com designs aprimorados.

A Oficina1 foi ofertada a professores em formação inicial do curso de Licenciatura em Matemática da Universidade Presbiteriana Mackenzie. Com duração de 1h30, a atividade prática aconteceu presencialmente, antes da pandemia de Covid-19, durante o Workshop de Matemática em Campos do Jordão, para o total de 25 participantes.

A Oficina2 foi ofertada a professores em formação continuada de uma escola da rede pública de Ensino Fundamental II, localizada em Ribeirão Pires. Com duração de 1h30, a atividade prática aconteceu presencialmente, antes da pandemia de Covid-19, durante um curso exclusivo de Preparação de Material Didático, desenvolvido pelo Laboratório de Matemática, no campus Higienópolis da UPM, para 15 professores.

Devido ao pouco tempo disponibilizado para as oficinas, durante os encontros, os participantes ficaram imersos nos recursos tecnológicos através das atividades roteirizadas propostas: instalação de dois aplicativos de RA e manipulação de um objeto 3D através de seus movimentos básicos (esquerda-direita, para cima para baixo e rotação).

O conteúdo matemático discutido foi o movimento de sólidos geométricos. Apenas um assunto foi abordado, pois foi necessário despender um tempo maior para apresentação da tecnologia de RA e seus princípios e, também, a instalação e uso de alguns recursos das ferramentas de RA, Augment e GeoGebra 3D.

Para os dois aplicativos utilizados foi necessário o uso do dispositivo móvel com câmera. A RA exige uma câmera e, na maior parte dos experimentos, esta câmera deve ser movimentada pelo cenário real. Na Oficinal todos os participantes utilizaram o celular, exceto um professor que utilizou um tablet. Os participantes instalaram os aplicativos em dispositivos com Android e apenas um deles possuía Iphone com o sistema IOS instalado. Na Oficina2 todos os participantes utilizaram celulares com Android.

A seguir, encontram-se as descrições dos dois aplicativos utilizados nas oficinas e o passo-a-passo para realizar a atividade roteirizada sobre o movimento de um sólido geométrico. É importante ressaltar que o objetivo das oficinas era apresentar a tecnologia de RA e suas possibilidades na exploração da matemática, em particular, de sólidos geométricos.

\section{Augment - 3D Augmented Reality}

O aplicativo Augment foi instalado pelos participantes das oficinas em seus respectivos dispositivos móveis para que pudessem manipular a ferramenta e terem as próprias experiências com a tecnologia de RA.

Ao abrir o aplicativo, diferentes objetos 3D são disponibilizados para o usuário. Foi selecionado o globo terrestre por ele representar um sólido geométrico (Figura 3).

O sólido virtual é posicionado sobre a imagem captada pela câmera do dispositivo móvel em tempo real. Neste caso, o celular estava sendo apontado para a página de um livro e sobre ele uma caneta vermelha. 
É possível manipular o objeto movimentando, rotacionando, aumentando ou diminuindo o tamanho. Para isso, é necessário utilizar os dedos da mão sobre a tela do celular.

\section{Figura 3 - Interfaces Augment}

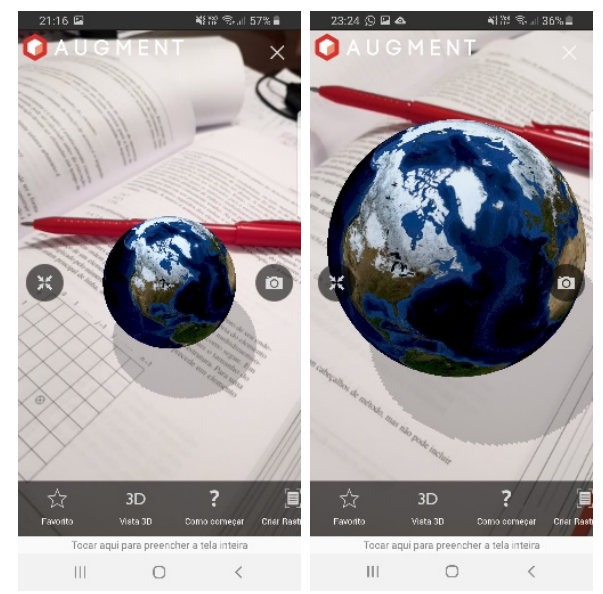

Fonte: Criado pelas autoras.

O aplicativo também permite que o usuário aplique o objeto escolhido sobre um marcador (uma superfície de referência) que pode ficar parado enquanto o celular é movimentado ao redor do objeto que está sobre o marcador, permitindo, assim, que o objeto seja visto sob diferentes perfis. É como se o usuário estivesse "andando" ao redor do objeto parado, analisando-o em diferentes visões. Como sugestão, o marcador pode ser uma figura de uma página específica de um livro; toda vez que o aplicativo estiver aberto e a câmera do celular posicionada em direção ao marcador, o objeto 3D específico é plotado sobre a página do livro. Essa funcionalidade é denominada "Criar Rastreador".

\section{GeoGebra 3D}

O aplicativo GeoGebra 3D cria e manipula construções geométricas em 3D através de suas características matemáticas. Ele foi instalado pelos professores participantes em seus respectivos dispositivos móveis.

Ao abrir o aplicativo, criou-se uma pirâmide utilizando a ferramenta básica "Pirâmide", que é uma das primeiras opções apresentadas na interface para o usuário (Figura 4).

O próximo passo foi selecionar a opção RA, que fica no canto direito da tela onde o objeto criado aparece (Figura 4). Uma superfície onde o objeto virtual será posicionado é reconhecida pela aplicação da RA se o usuário movimentar vagarosamente a câmera do celular. Esse reconhecimento é identificado pelo usuário quando uma malha brilhante e na cor branca aparece na tela (Figura 5). 


\section{Figura 4 - Interface da Calculadora Gráfica GeoGebra 3D}

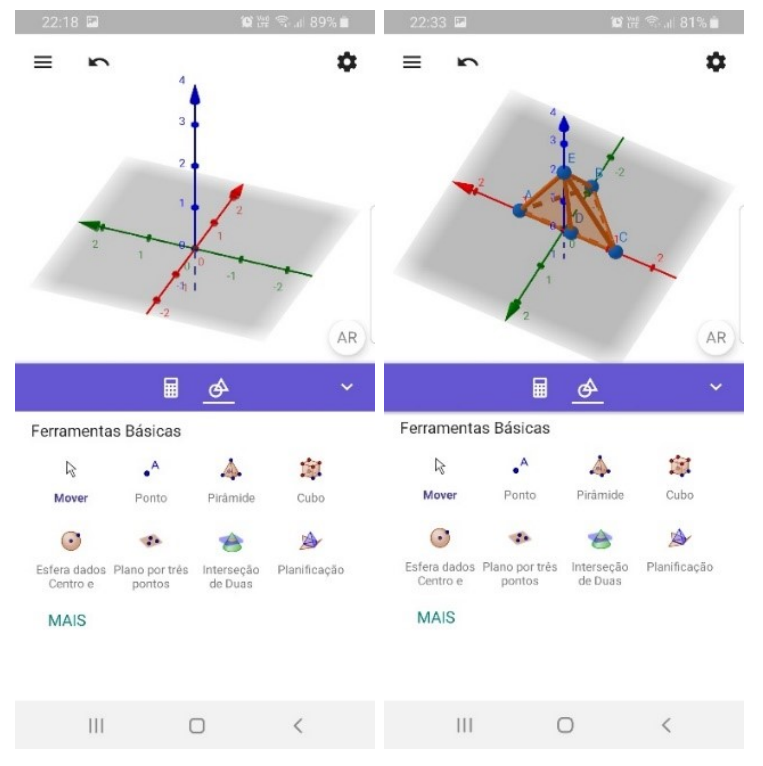

Fonte: Criado pelas autoras.

Após o reconhecimento de uma superfície, ou seja, depois que a malha surgiu, basta clicar no centro da mesma e o sólido construído (pirâmide) aparece fixo na posição clicada. $\mathrm{O}$ fundo da imagem continua sendo o cenário real (Figura 5).

Agora, com os dedos, o usuário é capaz de manipular o sólido, movimentando-o de um lado para outro e/ou aumentando ou diminuindo o seu tamanho (Figura 5).

\section{Figura 5 - Interface GeoGebra com objeto 3D plotado no cenário real}

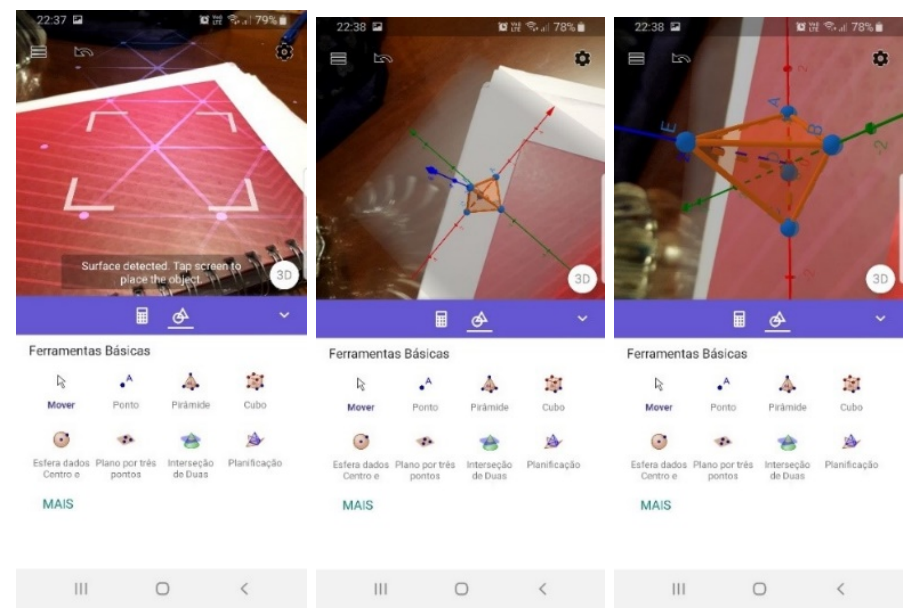

Fonte: Criado pelas autoras.

O GeoGebra 3D oferece opções de configurações para o objeto 3D manipulado, tais como transparência, cor e formato de linha (Figura 6). Essas configurações opcionais podem colaborar para uma maior clareza e/ou nitidez da superfície do sólido e facilitar, de alguma forma, a compreensão da dimensão e dos movimentos do objeto manuseado. 
Figura 6 - Interface do aplicativo GeoGebra 3D com RA e as opções de manipulação do objeto 3D

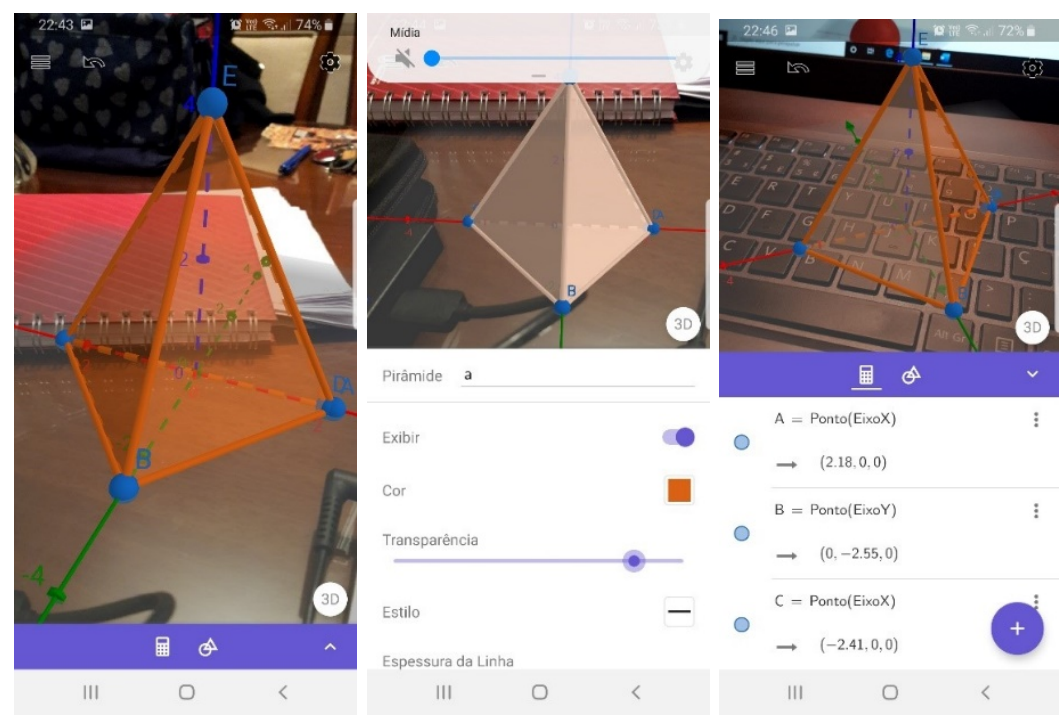

Fonte: Criado pelas autoras.

As Oficinas 1 e 2 tiveram a participação ativa do grupo de professores (formação inicial e formação continuada). Foram analisadas as experiências dos participantes com foco nas dificuldades enfrentadas com o uso dos aplicativos e manipulação dos dispositivos móveis. Os dados coletados a partir dessas experiências foram conseguidos por meio de depoimentos de alguns participantes, com o intuito de identificar as percepções de cada um deles em relação ao uso da RA. Dados também foram coletados via questionários disponibilizados eletronicamente para os participantes.

\section{ANÁLISE DOS RESULTADOS}

Uma das autoras e professora-instrutora pôde acompanhar todas as ações desenvolvidas pelos participantes durante o desenvolvimento das atividades. Foi possível atender cada solicitação de ajuda e ouvir os medos e receios ao utilizar uma ferramenta de RA.

Com o acompanhamento da participação dos professores durante a realização das oficinas, pudemos observar que os professores tiveram uma certa resistência inicial no uso da tecnologia, por pré-julgarem difíceis, fato esse que é evidenciado na $1^{a}$ etapa descrita por Engeström (1987) sobre questionamentos, crítica ou rejeição de alguns aspectos da prática corrente. Essa resistência foi notada desde a instalação dos aplicativos até o uso inicial deles. É importante explicitar o perfil dos professores participantes porque interferiu diretamente na rejeição inicial da atividade (Figura 7). 


\section{Figura 7 - Levantamento de dados}

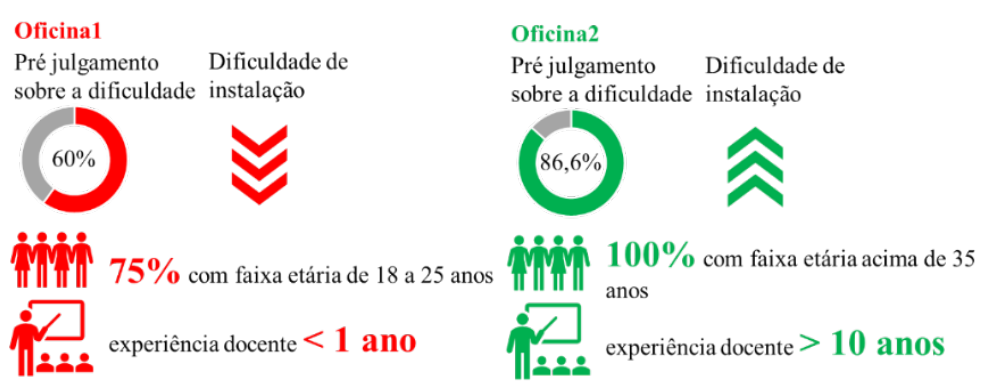

Fonte: Criado pelas autoras.

Os sujeitos de cada oficina possuíam perfis muito diferentes. Os participantes da Oficina1 eram, em sua maioria (aproximadamente 75\%), de professores em formação e com idade na faixa de 18 a 25 anos (Figura 7). Os participantes da Oficina2 eram, em sua totalidade, de professores que já atuavam a mais de dez anos na prática docente e com idade superior a 35 anos (Figura 7).

Na Oficina2 os participantes tiveram mais dificuldade para instalação dos aplicativos de RA e medo para manipulá-los. Isso se deve ao fato de a tecnologia não fazer parte do cotidiano de todos eles, nem mesmo fora da sala de aula. Os participantes da Oficina1, em sua maioria jovens, se mostraram um pouco mais confortáveis e menos resistentes às ações propostas (Figura 7). Eles convivem diretamente com a tecnologia, dentro e fora da sala aula, e são mais acostumados com o manuseio do celular.

Após os primeiros passos das atividades propostas, os professores, de forma geral, se sentiram mais confortáveis e confiantes no uso dos recursos tecnológicos e passaram a realizar as atividades com mais motivação, o que atende à $2^{a}$ etapa, na qual a análise da situação que envolve transformações mentais, discursivas ou práticas da situação em questão, permitiu descobrir causas ou mecanismos exploratórios.

Nas oficinas, o papel de cada participante não foi isolado e proporcionou momentos de reflexão sobre a situação. Toda essa mudança na percepção das ações e aceitação da atividade foi a existência dos preconceitos em comum, que minimizou as diferenças entre os professoresalunos, nivelou os sujeitos, permitindo que trabalhassem juntos para maximizar o aprendizado de todos eles. Dessa forma, a oficina deixou de ser algo burocrático e obrigatório e passou a ser um momento de diversão, curiosidade e aprendizagem.

Nos dois cenários, os professores foram, ao longo das oficinas, analisando a viabilidade de aplicação das atividades propostas em algumas aulas específicas de Matemática. À medida que foram aprendendo a interagir com as ferramentas, principalmente o GeoGebra 3D, os professores passaram a questionar: "Consigo fazer... na ferramenta?". Essas observações evidenciam a $3^{\text {a }}$ etapa, "modelando", com a construção de um modelo da nova ideia, que explique e ofereça uma solução para a situação dada como problema.

Foi possível notar a satisfação em aprender e o quão confortável já estavam com os primeiros passos no uso da tecnologia, permitindo a aproximação da teoria (oficina) e a prática (sala de aula) ao tentarem encaixar alguns poucos recursos com os conteúdos pedagógicos. 
Alguns professores até mesmo narraram a possível reação de seus alunos e o impacto positivo que a atividade poderia trazer para o processo de ensino-aprendizagem, configurando a $4^{a}$ etapa "examinando o modelo": experimentação do modelo, visando perceber sua dinâmica, potencialidade e limitações. Como o foco das oficinas era apresentação da tecnologia de RA, não houve tempo suficiente para explorar as potencialidades das ferramentas. Apenas algumas curiosidades de poucos professores foram sanadas, enquanto outros ainda finalizavam ações pré-determinadas.

Na Oficina1, mais recursos, além da apresentação das ferramentas, foram exibidos quando comparamos com a Oficina2. Isso se deve ao perfil dos participantes, conforme mencionado anteriormente. A etapa 3 demorou mais tempo na Oficina2 porque os professores tinham mais dificuldades até mesmo para lidar com o dispositivo móvel e, consequentemente, a $4^{\text {a }}$ etapa não teve muito êxito. Possivelmente em uma segunda oportunidade para desenvolvermos uma segunda etapa de oficinas, teríamos um rendimento melhor. O perfil mais jovem dos participantes da Oficinal propiciou um desenvolvimento mais rápido para as etapas 1 a 3 e, consequentemente, houve tempo para os professores chegarem na etapa 4 e requererem a exploração de mais recursos das ferramentas, já vislumbrando a sala de aula.

Apenas alguns professores da Oficina1 conseguiram chegar na etapa 5 - implementando o modelo. Ao analisar algumas características deste grupo seleto, percebeu-se que eram alunos de graduação do curso de Licenciatura em Matemática que já frequentaram a disciplina de Tecnologias Digitais oferecida na grade curricular e tinham conhecimento de RA (Figura 8). Estes professores avançaram pelas primeiras etapas mais rapidamente e, ao esperar pelos demais colegas, aproveitaram o tempo para atender às suas necessidades de sala de aula, implementando modelos entre eles.

Um dos pontos que chamou a atenção foi a participação dos professores que opinaram sobre a viabilidade e possível produtividade no uso de RA em sala de aula. A troca de experiências e a reflexão sobre a prática pedagógica no ensino da Matemática enriqueceram consideravelmente as oficinas.

Figura 8 - Resultados e Reflexões

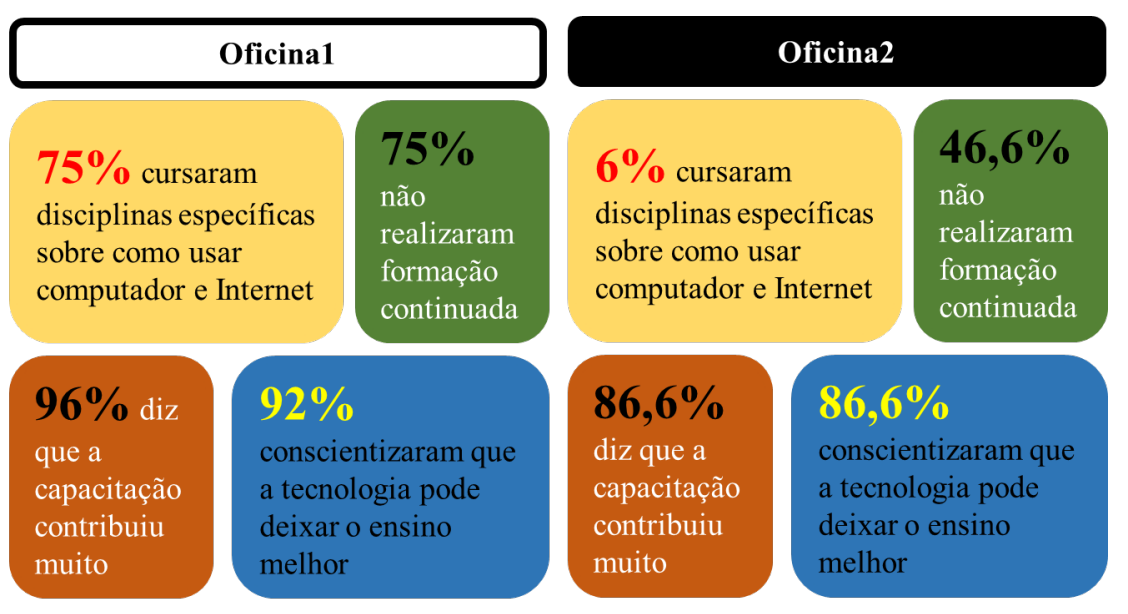

Fonte: Criado pelas autoras.

Com os depoimentos espontâneos colhidos a partir das experiências e os questioná- 
rios disponibilizados constatou-se o interesse dos professores de "imediatamente" colocar em exercício o uso de RA nas práticas pedagógicas como ferramenta nos processos de ensinoaprendizagem. De acordo com a Figura 8, 96\% dos participantes na Oficinal e 86,6\% dos participantes na Oficina2 disseram que a formação contribuiu de modo importante para o conhecimento e para o uso de uma ferramenta tecnológica para o ensino da Matemática. Os professores passaram a ter segurança no uso do dispositivo e dos aplicativos de RA ao ponto de decidirem, por conta própria, explorar outros recursos dos aplicativos. Tais depoimentos configuram as três últimas etapas do ciclo expansivo de Engeström (1987).

Um dado significativo foi a porcentagem de professores que se conscientizaram sobre a importância do uso da tecnologia no contexto de ensino e aprendizagem, na tentativa de obter um processo de melhor qualidade. A Figura 8 mostra que o nível de conscientização na Oficina1 foi maior que na Oficina2. Provavelmente essa pequena diferença pode ter relação com o perfil dos participantes. Professores com mais tempo de docência podem ter algum receio de serem substituídos pela tecnologia e acreditam no tradicionalismo. Ouvimos em alguns momentos, na Oficina2, comentários como: "sempre dei aula assim e sempre deu certo".

Consideramos que a duração das oficinas foi reduzida para um aprendizado aprimorado dos professores com relação aos aplicativos, mas o suficiente para despertar a curiosidade deles e fazer com que busquem se familiarizar com o uso das ferramentas e se sintam seguros ao incluí-las no plano de ensino dos conteúdos matemáticos.

Por mais que os professores convivam com tecnologias no seu dia a dia, o receio, muitas vezes gerado pelo despreparo em usar TDIC na prática didático-pedagógica, existe. Acredita-se que a formação continuada para o uso de tecnologias é importante para que o professor se sinta confiante com o uso delas.

De acordo com os relatos dos professores, durante e após as oficinas, é importante considerar que, em os cursos de formação, sejam disponibilizados roteiros práticos de como usar, onde usar e em qual conteúdo da Matemática aplicar. Segundo os participantes, esses roteiros serviriam como sugestão para estimular o uso de TDIC e colaborar para a criatividade dos professores durante o planejamento de suas aulas com aplicação de tecnologias.

$\mathrm{Na}$ Oficina2, todos os professores relataram ter dificuldade em inserir recursos tecnológicos na sala de aula, devido a estrutura da escola pública e o poder aquisitivo dos alunos para possuir um dispositivo móvel de qualidade que possa suportar aplicativos de RA. Assim, é importante ponderar sobre a melhor forma de inserir tecnologias nos diferentes cenários escolares. Dentre os participantes da Oficina1 e Oficina2, mais de 95\% garantem que possuem tecnologia mais avançada em casa do que no ambiente escolar.

\section{CONSIDERAÇÕES FINAIS}

Este artigo é resultado de um projeto de formação de professores de Matemática para o uso de tecnologias digitais e com propostas de ações inovadoras. Tem como objetivo identificar, 
a partir de reflexões apresentadas pelos participantes em duas oficinas realizadas no contexto da Realidade Aumentada (RA), contribuições desse processo formativo. Considerou-se que uma ferramenta tecnológica pode dar apoio ao planejamento de práticas pedagógicas no ensino de Matemática e permitir o engajamento dos alunos em um processo de aprendizagem.

A finalidade das duas oficinas ofertadas foi dar suporte tecnológico aos professores participantes, na tentativa de incentivá-los e motivá-los para a transformação digital em sala de aula. Aproveitou-se a oportunidade de reunir professores para investigar o quão consciente é o professor sobre a necessidade de formação e/ou atualização na área de tecnologias para o ensino da Matemática, para identificar, a partir de reflexões apresentadas pelos participantes, contribuições desse processo formativo e para coletar dados para a preparação de formações com designs aprimorados e motivadores.

Dois aplicativos de RA foram instalados pelos participantes no dispositivo móvel de cada um deles e apresentados através de uma atividade de movimentação de sólidos. Os aplicativos selecionados foram: GeoGebra 3D com RA e Augment.

O GeoGebra 3D com RA é um aplicativo de realidade aumentada desenvolvido para a educação Matemática e diferentes autores contribuem constantemente para o acervo de material didático. O Augment é um aplicativo de uso geral que pode ser adaptado para o ensino da Matemática e, consequentemente, possui poucos documentos de ajuda e acervo de material didático. O GeoGebra 3D despertou maior curiosidade e interesse dos participantes por ser uma ferramenta desenvolvida especificamente para a aprendizagem de Matemática. O Augment foi desprezado pela maior parte dos participantes por não apresentar os recursos necessários de manipulações matemáticas mais avançadas.

Percebeu-se que as oficinas, Oficina1 e Oficina2, embora com os respectivos tempos reduzidos, foram aproveitadas em sua totalidade com as ferramentas de realidade aumentada. $\mathrm{O}$ tempo de 1h30, embora insuficiente para maior familiarização dos professores com os recursos tecnológicos, mostrou-se motivador.

Para a construção de uma nova formação de professores, sugere-se um tempo maior de imersão para melhor aproveitamento da tecnologia de RA e o uso de seus recursos. Foi recomendado, pelos participantes das atividades Oficina1 e Oficina2, reuniões de aproximadamente três horas e que pudessem se repetir por dois ou três encontros, totalizando de seis a nove horas de curso. Esses números ainda não foram validados e serão analisados.

Consideramos interessante ter um tempo durante a oficina para que os participantes possam preparar seu próprio recurso com o uso dos aparatos tecnológicos aprendidos. Cada recurso criado seria apresentado aos demais professores que opinariam sobre a possível prática. Ao final da oficina, diferentes recursos estariam criados e serviriam como um ponto inicial de uso a todos os participantes. Os momentos de troca de experiências são de grande valia para a formação do professor e podem criar uma comunidade de prática no ambiente escolar. O planejamento de preparação dos recursos, durante a oficina, também seria uma forma de evidenciar a necessidade de se ter um tempo para preparar um bom material de apoio com o uso de TDIC. 
O contato direto com as ferramentas tecnológicas é essencial para que os professores possam adquirir confiança, ter maior familiaridade com o assunto a ser explorado e entender a relação do conteúdo com a ferramenta. Com isso, os recursos seriam mais bem planejados e a qualidade do ensino aprimorada.

As duas oficinas descritas cumpriram o seu objetivo primordial que era a conscientização de professores sobre a importância do uso de tecnologias no ensino da Matemática. Os dados mostraram que muitos participantes, que nunca tiveram contato com a tecnologia na época da graduação, não se preocupam com a necessidade de fazer parte de projetos de formação continuada. Foram justamente esses professores que mais se surpreenderam com a capacidade das ferramentas tecnológicas para melhoria do processo ensino-aprendizagem e que afirmaram o quão útil foi a oficina para o aperfeiçoamento do professor. Consequentemente, um passo importante para auxiliar o professor a decidir se a ferramenta tecnológica pode ser usada como ferramenta pedagógica dentro do seu contexto.

Consideramos que a metodologia de design based research (design experiments) para as próximas oficinas a serem desenvolvidas é uma metodologia que permitirá um aprimoramento das atividades para professores participantes e a descoberta de relações entre teoria educacional, artefato projetado e prática. (CARDOSO; COIMBRA; MATEUS, 2018).

Design Based Research é uma metodologia sistemática, porém flexível, que visa melhorar as práticas educacionais por meio de análise, design, desenvolvimento e implementação de iterativos, com base na colaboração entre pesquisadores e profissionais em contextos do mundo real, considerando princípios e teorias de design sensíveis ao contexto. (MAZZARDO et al., 2016).

Nosso objetivo é construir e manter, de forma contínua, um projeto que envolva tecnologia e ensino para professores de Matemática. As oficinas ofertadas, descritas neste trabalho, foram uma preparação para a continuação do projeto proposto. 


\section{REFERÊNCIAS}

AGOSTINHO, I. R. H.; GROENWALD, C. L. O. As tecnologias digitais da informação e comunicação como um recurso didático no currículo de matemática. UNICIENCIA, v. 34, p. 153-170, 2020.

ARTIGUE, M. The future of teaching and learning mathematics with digital technologies. In: HOYLES, C.; LAGRANDE, J.-B. (Org.). Mathematics Education and TechnologyRethinking the Terrain. [S.1.]: Springer, 2010.

ASSIS, L. S. Concepções de Professores de Matemática quanto à utilização de objetos de aprendizagem - um estudo de caso do projeto RIVED-BRASIL. 2005. Dissertação (Mestrado em Educação Matemática) - Pontifícia Universidade Católica de São Paulo, São Paulo, 2005.

AUGMENT. The platform for 3D and augmented reality product visualization. 2020. Acesso: fev. 2020. Disponível em: <http://augment.com.>

BITTAR, M. Possibilidades e dificuldades da incorporação do uso de softwares na aprendizagem da matemática. um estudo de caso: o software aplusix. In: SEMINÁRIO INTERNACIONAL DE PESQUISA EM EDUCAÇÃO MATEMÁTICA (SIPEM), 3., 2006, Águas de Lindoia. Anais [...]. Recife: SBEM, 2006. v. único, p. 1-12.

CARDOSO, A.; LAMOUNIER, E. A realidade virtual na educação e treinamento. In: FUNDAMENTOS E TECNOLOGIAS DE REALIDADE VIRTUAL E AUMENTADA, 2006, Belém. Livro do Pré-simpósio do VIII Symposium on Virtual Reality. Belém: SVR, 2006. v. único, p. $304-312$.

CARDOSO, T.; COIMBRA, T.; MATEUS, A. Análise matemática e realidade aumentada: um estudo no ensino superior em Portugal. Debates em Educação, v. 10, n. 22, p. 271-283, 2018.

ENGESTRÖM, Y. Learning by Expanding: An Activity-Theoretical Approach to Developmental Research. Helsinki: Orienta-Konsultit, 1987.

GEOGEBRA. GeoGebra Aplicativos Matemáticos. 2020. Disponível em: GeoGebra.org. Acesso: fev. 2020.

KIRNER, C.; TORI, R. Fundamentos de realidade aumentada. In: FUNDAMENTOS E TECNOLOGIAS DE REALIDADE VIRTUAL E AUMENTADA, 2006, Belém. Livro do Présimpósio do VIII Symposium on Virtual Reality. Belém: SVR, 2006. v. único, p. 22 - 38.

MACEDO, A. C. Ensino e aprendizado de geometria por meio da realidade aumentada em dispositivos móveis: um estudo de caso em colégios públicos do litoral paranaense. 2018. Dissertação (Mestrado em Educação) — Universidade Federal do Paraná, Curitiba, 2018.

MARTINS, J. S. Situações práticas de ensino e aprendizagem significativa. Campinas: Autores Associados, 2009.

MAZZARDO, M. D. et al. Design-based research: desafios nos contextos escolares. In: CONGRESSO IBERO AMERICANO EM INVESTIGAÇÃO QUALITATIVA, 5., 2016, Porto. Anais [...]. Porto, 2016. v. 1, p. 952-961.

MORENO-ARMELLA, L.; SRIRAMAN, B. Symbols and mediation in mathematics. In: SRIRAMAN, B.; ENGLISH, L. (Ed.). Theories of Mathematics Education: Seeking new frontiers. Berlim: Springer, 2010. p. 213-232. 
OLIVEIRA, C. A. Estratégias didáticas de realidade aumentada (ra) no ensino da matemática. In: SIMPÓSIO INTERNACIONAL DE EDUCAÇÃO E COMUNICAÇÃO, 9., 2018, Aracaju. Anais [...]. Aracaju: Unit, 2018. v. 1, p. 1-16.

OLIVEIRA, D. N. S. Percepção dos docentes sobreo uso dos tablets na escola. 2014. Monografia (Especialização em Fundamentos da Educação) - Universidade Estadual da Paraíba, João Pessoa, 2014.

OLIVEIRA, M. K. Vygotsky - Aprendizado e desenvolvimento: um processo sócio-histórico. São Paulo: Scipione, 2002.

PACHECO, M. L. S.; LOPES, R. P. Tic e trabalho docente: das dificuldades à resistência ao uso de tecnologias no processo educativo. In: SEMANA DA LICENCIATURA, 16., 2019, Jataí. Anais [...]. Jataí, 2019. v. 1, p. 353 - 367.

ROBERTO, R. Desenvolvimento de Sistema de Realidade Aumentada Projetiva com Aplicação em Educação. 2012. Dissertação (Mestrado em Ciência da Computação) - Universidade Federal de Pernambuco, Recife, 2012.

RODRIGUES, C. S. C.; PINTO, R. A. M.; RODRIGUES, P. F. N. Uma aplicação da realidade aumentada no ensino de modelagem dos sistemas estruturais. Revista Brasileira de Computação Aplicada, Passo Fundo, v. 2, n. 2, p. 81-95, 2010.

SANTOS, M. P. Educação continuada do professor de Matemática: Uma investigação sobre grupo de estudos no coletivo escolar. 2011. Dissertação (Mestrado em Educação Matemática) — Universidade Bandeirante de São Paulo, São Paulo, 2011.

SILVA, R. C. D.; VASCONCELOS, C. A. Realidade aumentada como apoio à aprendizagem de poliedros. Ensino da Matemática em Debate, v. 6, n. 2, 2019. Disponível em: https://revistas.pucsp.br/emd/article/view/41084. Acesso: fev. 2020.

TORI, R. Educação sem distância: as tecnologias interativas na redução de distâncias em ensino e aprendizagem. São Paulo: Senac, 2010. 